\title{
Changing the perspective to maintain the sustained development of Harbin's private economy
}

\author{
Xiaojun Lu ${ }^{1}$, Tingting $\mathrm{Xu}^{2}$, Chuanjing $\mathrm{Lu}^{3}$ \\ ${ }^{1}$ Harbin University of Commerce, 150028, China \\ ${ }^{2}$ Harbin Vocatinal College of Seience and Technology, 150000, China \\ ${ }^{3}$ Northeast Agricultural University, 150000, China
}

Keywords: Private economy; economic development; small and medium enterprises

\begin{abstract}
The proportion of private economy in our city's economic structure is increasing, which has exceeded $50 \%$, and is the backbone of our city's economic development. The state of its development has a direct impact on the economic development of our city. Therefore, to maintain the sustainability of the private economy, we should not rely solely on the government's policy, funds and other aspects of support, but also technology, brand, business model, management and other aspects of guidance, so as to make it constantly innovative, can quickly transform into productive forces and economy. Benefit. Private economy is an important engine of China's economic development, especially for the economic development of Heilongjiang Province. Under the new situation, the transformation and development of private economy not only need to successfully cope with the challenges brought by changes in the external environment, but also need to break through the bottleneck of the development of enterprises. In order to make Heilongjiang private economy sustainable development, it is particularly important to enhance the scientific and technological innovation ability of private enterprises. By increasing investment in scientific research and mastering the core technology, providing a good environment for the development of private enterprises, broadening the financing channels of enterprises, establishing an effective financial support system, promoting the upgrading of technological innovation and economic transformation and upgrading of private enterprises in Heilongjiang Province, and accelerating the development of private economy in our province.
\end{abstract}

\section{转变视角, 保持哈尔滨民营经济持续发展}

\author{
鲁啸军 ${ }^{1}$, 徐婷婷 ${ }^{2}$, 鲁传经 $^{3}$ \\ 1.哈尔滨商业大学, 哈尔滨 150028 \\ 2. 哈尔滨科学技术职业学院，哈尔滨 150000 \\ 3.东北农业大学，哈尔滨 150000
}

关键词：民营经济；经济发展；中小企业

摘 要: 民营经济在我市的经济结构中所占的比例越来越大, 已经超过了百分之五十, 是我市 经济发展的中坚力量。其发展的状态，直接影响到我市的经济发展状态，因此，保持民营经 济的持久性不能一味的靠政府的政策、资金等方面的扶持，还要再技术、品牌、经营模式、 管理等方面进行引导，使其不断创新，能迅速转换为生产力和经济效益。民营经济是我国经 济发展的重要引擎，对于黑龙江省经济发展尤其具有重要的意义。在新的形势下，民营经济 的转型与发展不仅需要成功应对外部环境变化带来的挑战, 更需要突破企业发展的自身制约 瓶颈。要想使黑龙江省民营经济可持续发展，增强民营企业科技创新能力显得尤为重要。通 过加大科研投入掌握核心技术，提供良好的民营企业发展环境，拓宽企业融资渠道，建立有 效的金融扶持体系，推动黑龙江省民营企业科技创新能力的提升与经济转型升级，加速我省 
民营经济的发展。

\section{1. 民营经济在哈尔滨经济发展中的意义和作用}

民营经济在哈尔滨经济发展中具有重要的作用和意义。首先，民营经济发展对国民经济的 持续、快速增长起到了支持、促进作用。是国民经济的重要增长点, 对国民经济起到了有效 的辅助和补充的作用。其次, 中小民营企业能够吸收大量人员就业, 为解决就业问题贡献力 量。中小民营企业一大特点就是面广量大、投资少、经营灵活, 对劳动者劳动技能要求低, 且大部分是从事劳动密集型产业, 因而能吸纳更多的劳动力, 能创造更多的就业机会。最后, 民营企业经济发展促进了基本经济制度的不断完善, 可以促进市场活跃。中小企业机制灵活, 可以利用自己的优势参与大企业不愿意涉足的服务领域以及新兴领域，能使市场活跃起来。 市场经济的繁荣是来自竞争的繁荣, 中小企业的竞争长期存在, 推动经济繁荣和市场的活跃。

\section{2. 哈尔滨民营经济发展中存在的问题}

尽管哈尔滨在发展民营经济方面做出很多努力，从经营范围、财税金融、行政管理等都做 出相关的规定, 以此着力点为哈尔滨民营经济的发展创造良好的政策环境, 但相对于我国其 他发达省份及地区来说，哈尔滨民营经济的政策环境还并不是很好，基于各种原因存在的问 题还有很多, 总体来说, 主要包括以下几个方面:

\section{1 民营经济总量偏少, 增速慢, 发展差距明显。}

与发达地区相比, 还存在明显差距。一是经济总量偏小，我省民营经济总量与民营经济比 较发达的江苏、广东等省份相比, 差距明显。二是增速相对较低。

\section{2 企业规模偏小, 总体竞争力有待提升。}

一是民营企业规模优势不突出，二是缺乏龙头企业带动效应，哈尔滨市民营企业缺少一批 竞争力强的大型企业和企业集团, 产业集聚程度偏低, 进而影响民营经济整体实力的提升。

\section{3 民营企业发展环境有待进一步提高。}

近年来，国家和省委、省政府相继出台了一系列推动民营经济发展的扶持政策，取消和下 放了部分行政审批事项，民营企业的发展环境得到了很大的改善。但仍存在一些问题，民营 企业期望把优惠政策落到实处、期望降低优惠政策门槛，加大扶持力度。从宣传角度看，知 晓率低，对政府出台的相关优惠政策了解的仅占一小部分这一方面说明企业对相关政策关注 度不够，另一方面也反映出政府有关部门与民营企业之间互动不足。从政策实施角度看，民 营企业仍有较大期望。希望可以进一步增加扶持政策、希望进一步减少收费、希望扩大税收 优惠政策受益范围。

\section{4 民营企业融资难、融资贵问题依然存在。}

近年来, 全省民营企业融资难、融资贵问题虽有一定缓解, 但是始终没有得到彻底解决, 资金问题仍然是困扰民营企业的重要问题。规模小、抵押担保不足是融资难的主要原因

\section{5 产业结构层次较低, 产业链条短。}

全省民营经济虽然发展较快，但仍存在产业基础薄弱、产业链条短、产品整体水平偏低、 技术含量较低、精深加工产品少等问题, 资源型产品、初级产品仍占主导地位。

\section{6 人才资源莫乏制约民营企业发展。}

民营企业面临的管理竞争、市场竞争和技术竞争，本质上是面临着人才的竞争。引进人才 难、留住人才难、用好人才更难，已经成为民营企业面临的普遍难题。

调查显示, 一是学历偏低, 二是管理人才、技术人才缺乏, 主要原因: 一方面是企业对高 
层次管理技术人才的吸引力和稳定性不够，待遇低是人才引进难的主要原因; 另一方面民营 企业自身对人才培养的投入不足，多数民营企业用人观念注重现实，愿意接受“招来即用”的 有工作经验的实用人才，不愿招收新人培养。

\section{7 科技创新能力薄弱, 企业发展后劲不足。}

民营企业大多数起步于小作坊，从门槛较低的领域进入，技术含量低，靠自有资金发展， 这是民营经济最初发展的客观条件所决定的，但是当企业发展到一定规模后，必须通过技术 创新提升竞争能力, 才能实现产业升级。调查结果显示, 全省民营企业存在着大型企业研发 投入相对不足, 小微型企业基本无研发机构, 自主研发能力薄弱等问题, 在较大程度上制约 了民营企业的发展。

\section{8 资源型民营企业面临困难。}

资源型企业以资源性产业为主导产业, 并形成了一条关联度高、对自然资源面临的形势越 来越严峻。一是煤城经济发展面临困难, 全省煤炭企业经营困难持续增加, 煤炭价格低迷、 能源结构调整、进出煤冲击、环保压力增大等诸多原因导致煤炭企业生产履步维艰。依赖性 强的产业链, 当主导产业发展受阻, 资源型企业面临的形势越来越严峻。一是煤城经济发展 面临困难，全省煤炭企业经营困难持续增加，煤炭价格低迷、能源结构调整、进出煤冲击、 环保压力增大等诸多原因导致煤炭企业生产履步维艰。

\section{3. 提升哈尔滨民营经济发展的对策}

哈尔滨市民营经济发展是涉及国计民生的大事，我们必须把加快民营经济发展的认识提高 到一个新的战略高度。哈尔滨市应该以深化改革突破体制上对民营经济发展的束缚，利用创 新的思路解决民营经济发展中遇到的难题。

\section{1 加强民营经济的科研能力，提高民营企业掌握关键核心技术的程度}

引导民营企业加大研发投入力度，努力掌握关键核心技术和自主知识产权，对传统产业进 行技术改造和提升，同时，加快培育以技术创新驱动为核心的新优势，从全局角度出发，建 立一个覆盖社会各个行业的技术创新体制，使得科技与市场能够得到充分交流与沟通，通过 政府建立的技术创新平台, 将创造力迅速转化成生产力, 最终实现从政府引导民营企业从技 术创新到市场自发创新的跨越[1]。

\section{2 调整优化资源配置, 通过产品创新、品牌创新和生产经营模式创新, 加强核心竞争能力 培养。}

民营经济已经趋于达到成熟和稳定阶段，其中的技术含量、资源占用、市场地位等方面有 了充分的表现和地位, 因此, 政府应当顺应社会转型发展, 合理的、有侧重的调整优化资源 配置, 要通过技术创新带动产品创新, 从中发掘企业新的市场机会, 制定科学管理目标, 提 高执行效率, 努力将价值链向研发、标准制定、销售服务和品牌建设拓展, 形成有特色的生 产经营模式, 最终转变成核心竞争能力。

\section{3 积极鼓励民营企业进入新兴产业和新兴业态，提升产业档次和水平}

任何的新兴行业和新兴业态通常在生命周中的引入期和成长期, 市场稳定格局尚未形成, 进入壁垒相对容易，对民营企业来着，是一个很好的机遇和挑战，本身民营企业具有体制灵 活、决策果断、转向简便的特点, 又能够增加民营企业的技术含量、创新企业经营和管理模 式，适应市场发展趋势，提高整体产业的档期和水平。 


\section{4 促进民营企业国际化拓展}

有实力、有条件的企业应积极“走出去”参与对外投资、并购等国际化经营，努力在国际市 场获取技术、人才、知识产权、渠道、资源等要素，逐步实现研发、生产、销售的全球化布 局。也可以鼓励发展集群式对外投资，即是众多企业组成一个集群，一起到某一地区投资， 以形成配套服务获得外部规模的经济性。这种集群组织不仅能为企业带来设施共享、快捷获 取信息、技术、服务等便利条件, 还可以保持原有企业灵活机动、反应迅速等优点。对于缺 乏核心竞争力、抵御风险能力差、内部规模效应低的民营企业来说，无疑是提高其跨国经营 效率的捷径。

\section{5 要千方百计提高经营管理团队素质}

民营企业大多从简单的作坊式经营起步,处于产业链的中下游,企业管理者文化程度普遍 偏低，个人素质和管理水平都亟待提高，同时企业员工在企业中扮演创造者、接受者和传播 者的角色，但民企很少对员工进行培训,更缺乏对其职业生涯的规划,致使员工的文化素质、业 务能力难以提高。政府相关部门要采取行动,全力助推民企管理提高自身政治理论素质和企业 技能素质, 努力将企业培养成学习型组织, 企业应该把学习作为员工生活和工作的重要组成 部分,将终身学习理念根植于每个员工心中。一方面必须加大培训和学习的投入,给予管理者和 员工学习知识、技能的机会; 另一方面要培养企业的学习习惯, 营造自发学习的良好氛围,使管 理者和员工在不断学习和实践中与企业共同发展。

\section{6 提倡民营企业形成先进企业文化，努力为企业可持续发展提供动力保障。}

民营经济撑起了哈尔滨经济的半壁江山。然而,不少民营企业创业时风光,寿命却不长， 这种状况的产生, 企业文化建设不足是一个重要原因。正如哈佛商学院教授约翰·科特在其著 作 《企业文化与经营业绩》 中所指出的“企业文化对企业长期经营业绩有着重大的作用,在 新世纪企业文化很可能成为主宰企业兴衰的关键因素”。民企文化仍处于起步阶段,存在着一 些突出问题:一是只注重形式。忽视内涵。二是建设缺乏创新。三是家族血缘文化难以改变。 四是企业家和员工素质制约。

大量研究表明,一个民营企业要实现企业文化的真正建立至少需要 3-5 年甚至更长时间。民 营企业家对此必须有清醒的认识, 要用长期发展的文化理念替代落后观念,把培育企业文化过 程作为企业的长期战略，精心升级长期坚持，从而塑造适合自身发展、具有独特个性的企业文 化体系。

总之，政府在对民营企业支持方面逐步的转变，从政策支持、资金支持方面逐步放手，让 民营企业进入市场，适应市场，提高自身的竞争能力和合作能力，政府主要创建宽松的市场 环境，创建公平公正的竞争规则，同时对民营企业起到诸多方面的引导作用，让哈尔滨的民 营企业持续、稳定、健康的发展。

\section{[参考文献]}

[1]赵思坤.黑龙江民营经济发展的政治环境分析,[D].黑龙江大学出版社,2014(05)

[2] 问履金金. 黑龙江省跨境电子商务物流发展存在的问题及对策 [D]. 商业经 济,2016(04):11-12+85.

[3]崔澜 谢淑萍 张铭朔. 黑龙江省非正规金融与民营中小企业融资若干问题研究 $[\mathrm{J}]$. 金融经 济,2015,38(S1):65-67.

[4]刘波卢.彦萍.徐金玲.黑龙江省民营经济发展分析研究[J].统计与咨询,2015(06):28-32

[5]黄琪.福建省民营经济发展中的问题与对策研究[D].吉林大学出版社,2017(06): 